\title{
Massive pulmonary embolism presents as a seizure - Role of PERT team \& Catheter Directed Thrombectomy
}

\author{
MN Qureshi* and MB Alsarraj \\ Consultant Emergency medicine, King Faisal Specialist Hospital \& Research Centre, Riyadh, KSA
}

\begin{abstract}
We present a case of a 60 years old female with massive pulmonary embolism (PE), who presented as a seizure, eight weeks post mandibular surgery for cancer. She was severely hypoxic, hypotensive and confused on arrival to Emergency department (ED). She responded to high flow oxygen \& intravenous fluids and was diagnosed "massive PE" on Computed Tomography (CT). The immediate involvement of Pulmonary Embolism Response Team (PERT) led to her successful treatment in the form of Catheter Directed Thrombectomy (CDT).
\end{abstract}

\section{Introduction/Definition}

Massive PE is a life-threatening condition, which can present as cardiac arrest. It is defined as a PE with hemodynamic compromise (systolic arterial pressure $<90 \mathrm{~mm} \mathrm{Hg}$ or a drop of at least $40 \mathrm{~mm}$ $\mathrm{Hg}$ for 15 minutes or more) [1]. Submassive PE has has radiological evidence of right ventricular strain, but no hemodynamic compromise.

Seizure is a rare presenting symptom of PE. Dyspnea, collapse, syncope are the most common symptoms of massive PE [2,3].

In the International Cooperative Pulmonary Embolism Registry (ICOPER) of 2454 consecutive patients from 7 countries, $4.2 \%$ had massive PE. It demonstrated 90 day mortality rates of $58.3 \%$ in patients with massive PE versus $15.1 \%$ in sub-massive category [3]. In USA, approximately 150,000 patients/year are diagnosed with acute PE. A major proportion of these patients die from massive PE [4].

\section{Presentation}

A 60 years old female was brought via ambulance to the ED, after a sudden collapse and generalised tonic clonic seizure at home.

She was 8 weeks post surgery (mandibulectomy with bone graft insertion taken from the right fibula, radical neck dissection and hemithyroidectomy) for a squamous cell carcinoma of her mandible and was on adjuvant chemotherapy.

\section{On Arrival}

The patient had a heart rate (HR) of $133 / \mathrm{min}$, blood pressure (BP) of $90 / 62 \mathrm{mmHg} \&$ respiratory rate of (RR) $56 / \mathrm{min}$. Oxygen saturations (O2 sats) were $55 \%$ on room air and temperature of 36 Celsius.

Respiratory system examination revealed central trachea, bilateral resonant percussion but decreased air entry both lung bases.

She had regular tachycardia with no "pulsus deficit". There were no distended neck veins and heart sounds were normal. She had a Glasgow Coma score 14 (E4, M6, V4) with no focal neurological deficits or signs of meningitis.

\section{Initial Resuscitation and investigations in the first hour}

The patient was oxygenated with a rebreathe mask at 15 litres/ min, which increased her $\mathrm{O} 2$ sats to $95 \%$. After a total of 1.5 litres of Intravenous (IV) $0.9 \%$ saline (in $500 \mathrm{ml}$ boluses), the HR decreased to $128 / \mathrm{min}$ and BP increased to $124 / 85 \mathrm{mmHg}$.

\section{ED investigations}

ECG showed S1Q3T3 pattern with Right Bundle Branch Block (Figure 1).

Chest X-ray showed bilateral reduced vascular markings. Troponin \& lactate were raised to $68 \mathrm{ng} / \mathrm{L} \& 7.60 \mathrm{mmol} / \mathrm{L}$ respectively. Pro-BNP was normal.

Urea was creatinine were also raised to $14.1 \mathrm{mmol} / \mathrm{L}$ and 111 umol/L respectively.

WBC \& platelet counts were low.

Computed Tomography (CT) of chest with contrast was reported by radiologist as "massive PE" with right ventricular strain pattern (Video 1).

\section{Involvement of Pulmonary Embolism Response Team (PERT) and management plan}

The PERT team was immediately consulted by ED after the initial resuscitation.

It is a multidisciplinary team comprising a lead consultant, ICU consultant, interventional radiologist, hematologist and ED consultant for joint decision making in "high risk PE" cases.

Within 10 minutes of consultation with PERT, the patient was started on low dose heparin at $18 \mathrm{units} / \mathrm{kg} / \mathrm{hr}$ in the ED and

${ }^{\star}$ Correspondence to: MN Qureshi, Consultant Emergency medicine, King Faisal Specialist Hospital \& Research Centre, Riyadh, KSA, E-mail: qmuhammad@kfshrc. edu.sa

Received: June 19, 2020; Accepted: July 10, 2020; Published: July 14, 2020 


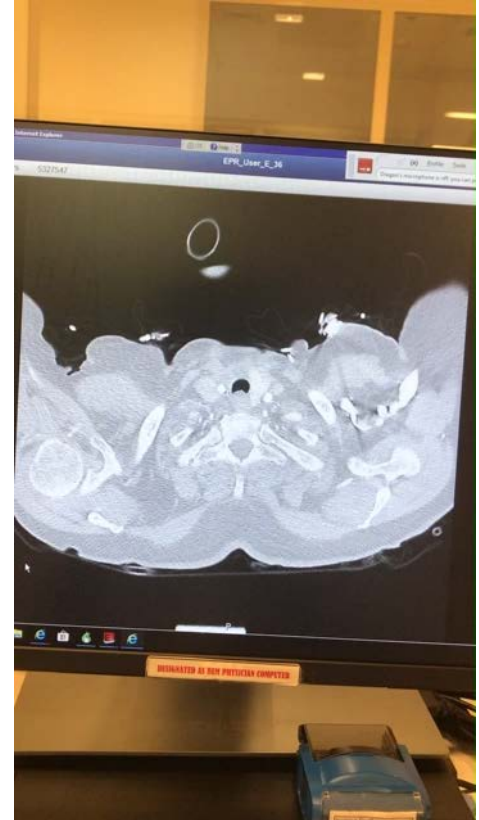

Video 1. Massive PE CT chest

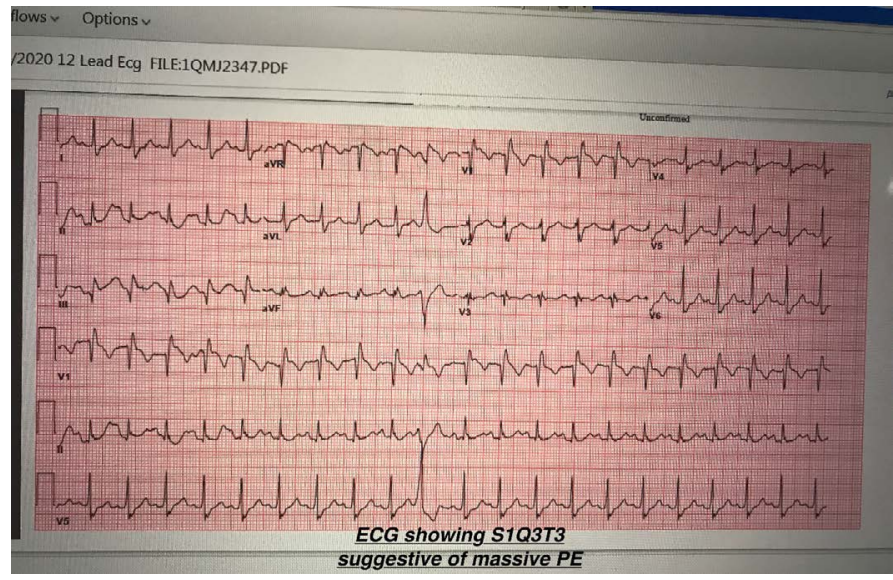

Figure 1. Massive PE ecg

patient prepared for "Catheter Directed (pharmaco-mechanical) Thrombectomy" (CDT).

The CDT procedure was carried out successfully within 1.5 hours of patient booking in ED. A large clot (Figures 2-4) was successfully removed from the main pulmonary artery (PA). Post procedure angiogram revealed $50 \%$ reduction in clot burden. A total of $10 \mathrm{mg}$ of alteplase was also used during the CDT process.

After the CDT, the patients' O2 sats increased to $98 \%$ on nonrebreathing mask with a stable tachycardia ranging between 120-130/ minute.

The patients Pulmonary Artery Pressure (PAP) was recorded as 52/28 $\mathrm{mmHg}$ (mean 38). Pre-procedure PAP was unfortunately missed. The patient was shifted to ICU after the procedure.

\section{Review after 24hrs in ICU}

Patient clinically improved with HR of $110-120 / \mathrm{min}$, BP of $130 / 80$ $\mathrm{mmHg} \& \mathrm{RR}$ of $24 / \mathrm{min}$. O2 sats were $97 \%$ on 6 litres of oxygen.
Troponin \& Pro-BNP had risen to $268 \mathrm{ng} / \mathrm{L}$ and $3682 \mathrm{pg} / \mathrm{ml}$ respectively. The renal functions had returned to normal. The Partial thromboplastin time (PTT) was normal despite patient being on heparin infusion.

Transthoracic Echocardiogram (ECHO) revealed significant dilatation of the Right Ventricle (RV) with moderate to severe reduction in systolic function. There was still a large residual clot in the main PA, partially obstructing the right PA.

IV Alteplase $2 \mathrm{mg} / \mathrm{hr}$ for $13 \mathrm{hrs}$ was commenced along with ongoing heparin infusion with close monitoring for any bleeding.

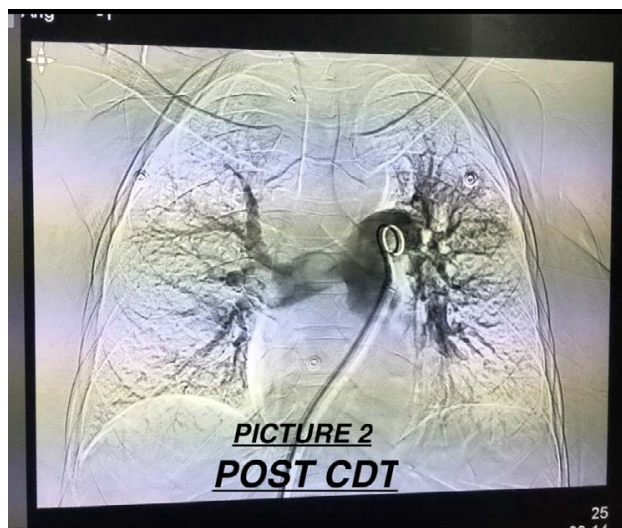

Figure 2a. Post CDT pic1

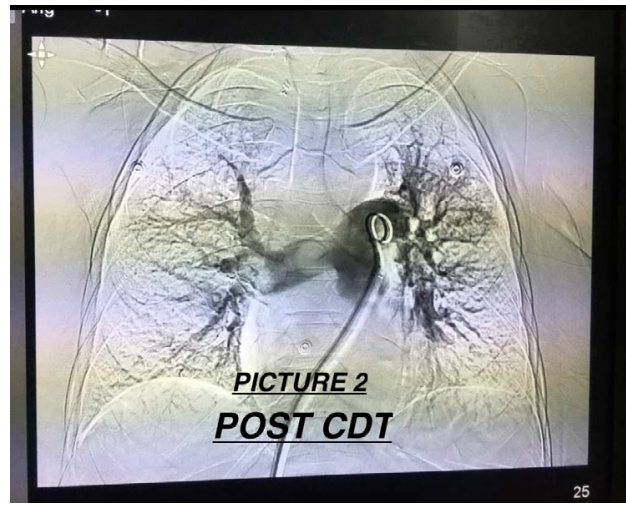

Figure 2b. Post cdt pic2

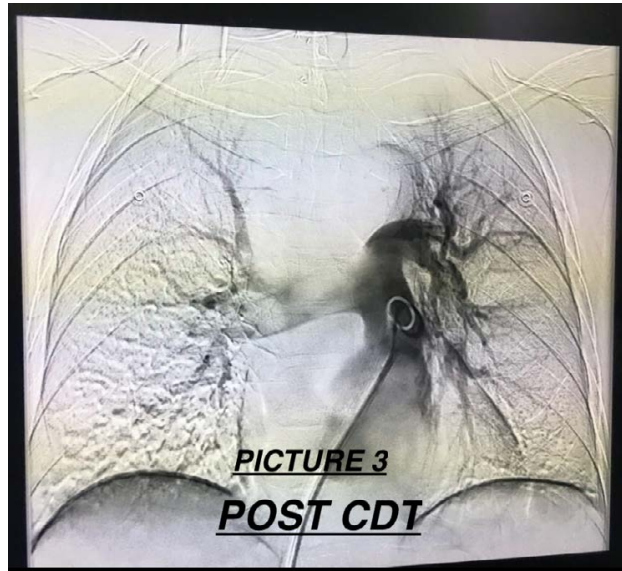

Figure 3. Post cdt pic3 


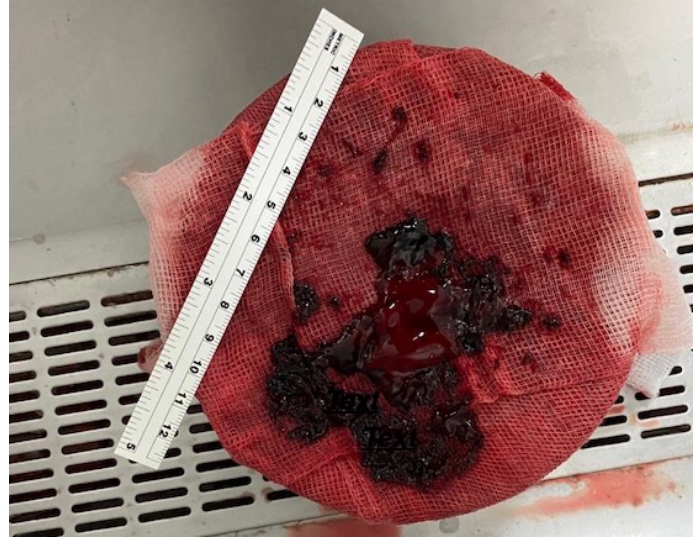

Figure 4. Massive PE clot

\section{Review after 48hrs in ICU}

Patient was clinically improved. HR ranged between $105-111 / \mathrm{min}$, $\mathrm{BP}$ was $135 / 70 \mathrm{mmHg} \& \mathrm{RR}$ was $18 / \mathrm{min}$. O2 sats were $100 \%$ on room air.

Repeat ECHO showed minimal thrombus in the right PA and significant improvement in the RV function.

Ultrasound Doppler of her right lower extremity (where he fibular bone graft taken) revealed right popliteal vein thrombosis.

The patients' PTT had increased to 60.9 seconds.

The patient completed the alteplase infusion without any significant bleeding. Patients' unfractionated heparin was switched on to Low Molecular Weight Heparin (LMWH).

\section{Course over the next one week}

Patient made a complete clinical \& hemodynamic recovery and was discharged with a follow up plan with the outpatient anticoagulation team.

\section{Discussion}

Seizure is a rare presentation of massive $\mathrm{PE}$, which is thought to be due to decrease in cerebral perfusion caused by reduced cardiac output $[5,6]$. Our patients' had provoked PE secondary to the thrombus, which developed in her operated right lower extremity.

Titrated IV fluids can be useful during the initial resuscitation for treating hypotension associated with massive PE but excessive fluid therapy can be detrimental, as it can further compromise RV function $[7,8]$.

Vasopressors should be started, if the hypotension is unresponsive to the fluid challenge. Dopamine is the first line vasopressor, recommended for shock associated with massive PE. Other vasopressors can be used in conjunction, if hemodynamic instability persists [9].

CT chest with contrast is a gold standard for diagnosing PE. Echocardiogram is the most appropriate diagnostic study for unstable $\mathrm{PE}$ patients, who are unfit to be transferred to CT scanner. It can also be used as a follow up investigation, after therapeutic interventions for PE. Other life threatening conditions like aortic dissection, which can have a similar presentation can also be diagnosed by using this modality $[10,11]$.

Cardiac biomarkers like Troponin and Pro-BNP are also used for risk stratification of massive PE after treatment has been carried out
[12]. This was the case with our patient where the rise in these markers after 24 hrs triggered additional treatment.

Radioisotope scanning is a very ancient method of diagnosing massive PE but has been superseded by modern spiral CT. D-dimers have no place in diagnosis of massive PE [13].

PERT is a multidisciplinary team for joint decision making in "high risk PE” cases. It leads to faster management, lesser length ICU stay and reduction in mortality [14].

Mechanical thrombectomy \& thrombolysis has been successfully utilised as an effective means of treating acute massive PE [14].

Systemic thrombolysis with a fibrinolytic agent reduces mortality in patients with massive PE, when compared to intravenous heparin alone [4]. In a meta analysis, the death and recurrence of PE was increased by approximately $50 \%$, when the massive PE was treated with IV heparin alone without concomitant use of thrombolytic agents [15].

9.1\% patients can have significant bleeding episodes post thrombolysis. Bleeding episodes increase proportionately, when thrombolysis and heparin infusion is used together [16].

The international bodies have unanimous opinion for using systemic thrombolysis for massive $\mathrm{PE}$, as it reduces mortality. A difference in approach exists, when using it for submassive PE. The American College of Chest Physicians (ACCP) recommends its use, when cardiovascular deterioration is evident. The European society of Cardiology (ESC) recommends using Pulmonary Embolism Severity index (PESI) along with further imaging and biomarker assessment before any treatment decision [16,17].

Incorporation of inferior vena cava (IVC) filter reduces recurrence of massive $\mathrm{PE}$ and consequently the mortality in patients with massive $\mathrm{PE}$ [17].

\section{References}

1. Dauphine, Christine, Bassam (2005) Pulmonary embolectomy for acute massive pulmonary embolism. The Annals of Thoracic Surgery 79(4):1240-1244.

2. Verstraete M, Miller GA, Bounameaux H, Charbonnier B, Colle JP, et al. (1988) Intravenous and intrapulmonary recombinant tissue-type plasminogen activator in the treatment of acute massive pulmonary embolism. Circulation 77(2):353-360. [Crossref]

3. Wagner Jr, Henry N, David C, Sabiston Jr, John G, et al. (1964) Diagnosis of massive pulmonary embolism in man by radioisotope scanning. New England Journal of Medicine 271(8):377-384. [Crossref]

4. Jerjes-Sanchez C, Ramírez-Rivera A, García MdeL, Arriaga-Nava R, Valencia S, et al. (1995) Streptokinase and heparin versus heparin alone in massive pulmonary embolism: A randomized controlled trial. Journal of thrombosis and thrombolysis 2(3):227-229.

5. Kucher N, Rossi E, DeRosa M (2006) Massive pulmonary embolism. Journal of Vascular Surgery 44(3):684-685.

6. Kucher N, Goldhaber SZ (2003) Cardiac biomarkers for risk stratification of patients with acute pulmonary embolism. Circulation 108(18):2191-2194.

7. Goldhaber SZ., Visani L, Rosa M De (1999) Acute pulmonary embolism: clinical outcomes in the International Cooperative Pulmonary Embolism Registry (ICOPER). The Lancet 353(9162):1386-1389.

8. Paul DS, Hull RD, Ghali WA, Patel KC, Olson RE, et al. (2003) Tracking the uptake of evidence: two decades of hospital practice trends for diagnosing deep vein thrombosis and pulmonary embolism. Archives of Internal Medicine 163(10):1213-1219.

9. Wolfgang K, Konstantinides S, Geibel A, Olschewski M, Heinrich F, et al. (1997) Management strategies and determinants of outcome in acute major pulmonary embolism: results of a multicenter registry. Journal of the American College of Cardiology 30(5):1165-1171. [Crossref]

10. Susan W, Quinlan DJ, Agnelli G, Eikelboom JH (2004) Thrombolysis compared with heparin for the initial treatment of pulmonary embolism: a meta-analysis of the randomized controlled trials. Circulation 110(6):744-749. [Crossref] 
11. Adam T, Galié N, Covezzoli A, Rossi E, Rosa MDe, et al. (2003) Right heart thrombi in pulmonary embolism: results from the International Cooperative Pulmonary Embolism Registry. Journal of the American College of Cardiology 41(12):22452251. [Crossref]

12. Shu-Hsu L, Wang YC, Wu YS, Huang SC, Lin CS (2016) A Rare cause of pulmonary embolism and seizure in a young man: Antiphospholipid Syndrome. Acta Cardiologica Sinica 32(2):247. [Crossref]

13. Joseph EM, Goldhaber SZ (1997) Pulmonary embolism presenting as seizures. Chest 112(3):840-842.
14. David MD, Piazza G (2016) Multidisciplinary pulmonary embolism response teams. Circulation 133(1):98-103.

15. Office of the Surgeon General (2008) The Surgeon General's call to action to prevent deep vein thrombosis and pulmonary embolism.

16. David J, Aujesky D, Moores L, Gómez V, Lobo JL, et al. (2010) Simplification of the pulmonary embolism severity index for prognostication in patients with acute symptomatic pulmonary embolism. Archives of internal medicine 170(15):1383-1389.

17. Guy M, Vicaut E, Danays T, Agnelli G, Becattini C, et al. (2014) Fibrinolysis for patients with intermediate-risk pulmonary embolism. $N$ Engl J Med 370:1402-1411. [Crossref]

Copyright: (C2020 Qureshi MN. This is an open-access article distributed under the terms of the Creative Commons Attribution License, which permits unrestricted use, distribution, and reproduction in any medium, provided the original author and source are credited. 